\title{
The Relation Between Clinical Phenotypes, GOLD Groups/Stages and Mortality in COPD Patients - A Prospective Multicenter Study
}

\author{
Kristian Brat (iD ${ }^{1,2}$ \\ Michal Svoboda ${ }^{2,3}$ \\ Jaromir Zatloukal ${ }^{4,5}$ \\ Marek Plutinsky ${ }^{1,2}$ \\ Eva Volakova (iD) 4,5 \\ Patrice Popelkova (iD ${ }^{6,7}$ \\ Barbora Novotna ${ }^{8}$ \\ Tomas Dvorak ${ }^{9}$ \\ Vladimir Koblizek (D) 10, I I \\ 'Department of Respiratory Diseases, \\ University Hospital Brno, Brno, Czech \\ Republic; ${ }^{2}$ Faculty of Medicine, Masaryk \\ University, Brno, Czech Republic; \\ ${ }^{3}$ Institute of Biostatistics and Analyses, \\ Ltd., Brno, Czech Republic; ${ }^{4}$ Pulmonary \\ Department, University Hospital \\ Olomouc, Olomouc, Czech Republic; \\ ${ }^{5}$ Faculty of Medicine, Palacky University, \\ Olomouc, Czech Republic; ${ }^{6}$ Pulmonary \\ Department, University Hospital \\ Ostrava, Ostrava, Czech Republic; \\ ${ }^{7}$ Faculty of Medicine, University of \\ Ostrava, Ostrava, Czech Republic; \\ ${ }^{8}$ Pulmonary Department, Bulovka \\ Hospital, Prague, Czech Republic; \\ ${ }^{9}$ Pulmonary Department, Mlada Boleslav \\ Hospital, Mlada Boleslav, Czech Republic; \\ ${ }^{10}$ Pulmonary Department, University \\ Hospital Hradec Kralove, Hradec \\ Kralove, Czech Republic; "Faculty of \\ Medicine in Hradec Kralove, Charles \\ University, Prague, Czech Republic
}

Correspondence: Kristian Brat Department of Respiratory Diseases, University Hospital Brno and Faculty of Medicine, Masaryk University, Jihlavska Street 20, Brno, 62500, EU, Czech Republic

Tel +420532232504

Email kristian.brat@seznam.cz
Introduction: The concept of phenotyping emerged, reflecting specific clinical, pulmonary and extrapulmonary features of each particular chronic obstructive pulmonary disease (COPD) case. Our aim was to analyze prognostic utility of: "Czech" COPD phenotypes and their most frequent combinations, "Spanish" phenotypes and Global Initiative for Chronic Obstructive Lung Disease (GOLD) stages + groups in relation to long-term mortality risk.

Methods: Data were extracted from the Czech Multicenter Research Database (CMRD) of COPD. Kaplan-Meier (KM) estimates (at 60 months from inclusion) were used for mortality assessment. Survival rates were calculated for the six elementary "Czech" phenotypes and their most frequent and relevant combinations, "Spanish" phenotypes, GOLD grades and groups. Statistically significant differences were tested by Log Rank test. An analysis of factors underlying mortality risk (the role of confounders) has been assessed with the use of classification and regression tree (CART) analysis. Basic factors showing significant differences between deceased and living patients were entered into the CART model. This showed six different risk groups, the differences in risk were tested by a Log Rank test.

Results: The cohort $(\mathrm{n}=720)$ was $73.1 \%$ men, with a mean age of 66.6 years and mean $\mathrm{FEV}_{1}$ $44.4 \%$ pred. KM estimates showed bronchiectases/COPD overlap (HR 1.425, p=0.045), frequent exacerbator (HR 1.58, $<<0.001$ ), cachexia (HR 2.262, $<<0.001$ ) and emphysematous (HR 1.786, $\mathrm{p}=0.015$ ) phenotypes associated with higher mortality risk. Co-presence of multiple phenotypes in a single patient had additive effect on risk; combination of emphysema, cachexia and frequent exacerbations translated into poorest prognosis (HR 3.075; $\mathrm{p}<0.001)$. Of the "Spanish" phenotypes, AE CB and AE non-CB were associated with greater risk of mortality (HR 1.787 and 2.001; both $\mathrm{p}=0.001$ ). $\mathrm{FEV}_{1} \%$ pred., cachexia and chronic heart failure in patient history were the major underlying factors determining mortality risk in our cohort.

Conclusion: Certain phenotypes ("Czech" or "Spanish") of COPD are associated with higher risk of death. Co-presence of multiple phenotypes (emphysematous plus cachectic plus frequent exacerbator) in a single individual was associated with amplified risk of mortality.

Keywords: chronic obstructive pulmonary disease; COPD, phenotypes, mortality, cluster, classification and regression tree; CART

\section{Introduction}

Of the non-communicable diseases, chronic obstructive pulmonary disease (COPD) ranked as the third leading cause of death worldwide after ischaemic heart disease and stroke. ${ }^{1}$ COPD is a heterogenic syndrome characterized not only by pulmonary 
involvement, but also by various extrapulmonary manifestations sometimes grouping in clusters of specific disease patterns. In the past decade, a concept of COPD phenotyping and treatable traits has emerged, reflecting specific clinical, pulmonary and extrapulmonary features of the each particular case. ${ }^{2-6}$ The main advantage of this concept is that COPD patients may receive a more personalized type of treatment. ${ }^{2,7}$

The most widely used phenotyping scheme was introduced in Spain eight years ago. Within this approach, COPD phenotypes were constructed on a basis of exacerbation history in the past 12 months and presence (or absence) of chronic bronchitis or bronchial asthma and COPD overlap (ACO). ${ }^{2,8}$ Four COPD phenotypes are recognized, including non-exacerbator (NE), asthmaCOPD overlap (ACO), frequent exacerbator with emphysema (AE non-CB), and exacerbator with chronic bronchitis $(\mathrm{AE} \mathrm{CB}){ }^{2}$ This phenotyping approach gained recognition also in several other countries. ${ }^{2,8}$ Of note, the Spanish approach recognizes the possibility of only one phenotype existence in a single COPD individual. ${ }^{2}$

An alternative phenotyping approach was introduced in the Czech Republic in 2013. Six clinical phenotypes of COPD have been defined, including emphysematous, bronchitic, asthma/COPD overlap (ACO), pulmonary cachexia, frequent exacerbator and bronchiectases with COPD overlap (BCO). ${ }^{6}$ Each of these clinical phenotypes has specific clinical, radiological, laboratory or functional appearance. ${ }^{6}$ At the same time, in our concept, each of these phenotypes is considered an independent treatable trait. ${ }^{6}$ The treatment strategy presented in the recent position paper of the Czech Pneumological and Phthisiological Society on COPD management is divided into five strata: risk elimination, basic treatment, phenotype-specific treatment, treatment of respiratory failure and palliative care, and treatment of comorbidities. ${ }^{6}$ When compared to the Spanish COPD management guidelines, an important difference is that we recognize the possibility of multiple clinical phenotypes' coexistence in a single COPD individual (one patient $=$ one or more phenotypes). ${ }^{6}$ This concept facilitates optimization of treatment strategy in relation to specific disease patterns of each COPD individual. ${ }^{6,9-11}$

Apart from treatment guidance, phenotypes may also have certain prognostic properties. ${ }^{12}$ In a recent study by Golpe et al, the two Spanish exacerbator phenotypes were associated with increased risk of long-term mortality compared to NEs and ACO individuals. ${ }^{12}$ To date, the potential prognostic value of Czech COPD phenotypes has not been assessed, despite the routine use of COPD phenotyping in the daily practice in the Czech Republic.

The primary aim of this study was to assess possible associations between presence of "Czech" COPD phenotypes and long-term mortality risk. The secondary aim was to evaluate how other COPD classifications ("Spanish" phenotypes and Global Initiative for Chronic Obstructive Lung Disease [GOLD] stages and groups) relate to mortality risk in our cohort. We hypothesized that the presence of certain clinical phenotype or co-presence of multiple phenotypes in a single patient (as defined by the Czech classification scheme of COPD) may be associated with increased risk of death. ${ }^{6}$

In some cases, the Czech clinical phenotypes may not be simply identifiable (e.g., without CT scanning). Therefore, we analyzed also the role of confounders (e.g., comorbidities, lung functions, clinical characteristics etc.) with regard to mortality risk in our cohort.

\section{Methods}

\section{Study Population}

Data for this particular study were extracted from the Czech Multicenter Research Database (CMRD) of COPD. ${ }^{13}$ Detailed description of the CMRD project, inclusion and exclusion criteria, etc. was published previously. ${ }^{13}$ Briefly, CMRD is a prospective, non-interventional multicenter project with a primary objective to assess morbidity, all-cause mortality and the natural disease course in patients with moderate to very severe COPD (i.e., with predicted value of Forced Expiratory Volume in 1 second $\left[\mathrm{FEV}_{1}\right.$ pred.] $<60 \%$ ). Secondary aims of the CMRD project are: to follow the stability of disease phenotypes over time and to study the real-life effectiveness of phenotype-specific therapies in COPD patients. The CMRD project was registered at the Czech Republic State Institute for Drug Control with the identifier 1301100001 and at ClinicalTrials.gov with identifier number NCT01923051.

Patients within the CMRD cohort were recruited in 14 centers providing specialized respiratory care between February 2013 and December 2016 and have since been followed up. All subjects signed a written consent form prior to study enrolment. Parameters assessed at enrolment included patient history data, demographics, symptoms assessment (dyspnoea - modified Medical Research Council [mMRC] score, COPD Assessment Test [CAT]), quality of life measures (St George's Respiratory 
Table I Baseline Characteristics of the Cohort $(N=720)$

\begin{tabular}{|c|c|c|}
\hline \multicolumn{3}{|l|}{ Demography } \\
\hline Male sex & & $526(73.1 \%)$ \\
\hline \multicolumn{2}{|l|}{ Age at inclusion } & $66.6(9.3)$ \\
\hline \multicolumn{2}{|l|}{ Age at diagnosis } & $58.7(10.9)$ \\
\hline Body Mass Index & & $27.1(6.0)$ \\
\hline \multirow[t]{3}{*}{ Smoking status } & Ex-smoker & $500(69.4 \%)$ \\
\hline & Non-smoker & $70(9.7 \%)$ \\
\hline & Smoker & $150(20.8 \%)$ \\
\hline \multicolumn{3}{|l|}{ Symptoms } \\
\hline \multirow[t]{5}{*}{ mMRC score } & 0 & $33(4.6 \%)$ \\
\hline & 1 & $137(19.0 \%)$ \\
\hline & 2 & $287(39.9 \%)$ \\
\hline & 3 & $148(20.6 \%)$ \\
\hline & 4 & $115(16.0 \%)$ \\
\hline CAT score & & I6.I (7.8) \\
\hline Fatigue & & $336(47.2 \%)$ \\
\hline Cough & & $523(72.6 \%)$ \\
\hline Expectoration & & $422(58.6 \%)$ \\
\hline Sputum production & & $39(5.4 \%)$ \\
\hline Hemoptysis & & $37(5.1 \%)$ \\
\hline Atopy & & 84 (II.7\%) \\
\hline Asthma & & $72(10.0 \%)$ \\
\hline \multicolumn{3}{|c|}{ Exacerbations (last 12 months) } \\
\hline Treated at home & & $0.8(1.4)$ \\
\hline$>0$ & & $296(41.1 \%)$ \\
\hline Treated at hospital & & $0.4(0.8)$ \\
\hline$>0$ & & $183(25.4 \%)$ \\
\hline Total & & $1.2(1.7)$ \\
\hline$>0$ & & 380 (52.8\%) \\
\hline \multicolumn{3}{|l|}{ Lung function tests } \\
\hline $\mathrm{FEV}_{\text {। }}$ (\% of predicted) & & 44.4 (II.4) \\
\hline $\begin{array}{l}\text { FVC (\% of } \\
\text { predicted) }\end{array}$ & & $70.0(17.3)$ \\
\hline IVC (\% of predicted) & & $73.1(17.4)$ \\
\hline $\mathrm{FEV} / \mathrm{FVC}(\%)$ & & $0.5(0.1)$ \\
\hline
\end{tabular}

(Continued)
Table I (Continued).

\begin{tabular}{|c|c|c|}
\hline RV (\% of predicted) & & $\begin{array}{c}\mathrm{N}=578 ; 189.4 \\
(59.0)\end{array}$ \\
\hline $\begin{array}{l}\text { TLC (\% of } \\
\text { predicted) }\end{array}$ & & $\begin{array}{c}\mathrm{N}=575 ; \quad I 12.4 \\
(25.8)\end{array}$ \\
\hline RV/TLC (\%) & & $\begin{array}{c}\mathrm{N}=538 ; 66.8 \\
(21.0)\end{array}$ \\
\hline IC/TLC (\%) & & $\begin{array}{c}\mathrm{N}=4 \mid 4 ; 42.1 \\
(24.6)\end{array}$ \\
\hline $\begin{array}{l}\mathrm{TL}_{\mathrm{CO}}(\% \text { of } \\
\text { predicted) }\end{array}$ & & $\begin{array}{c}\mathrm{N}=466 ; 52.1 \\
(21.9)\end{array}$ \\
\hline FeNO (ppb) & & $\begin{array}{c}\mathrm{N}=273 ; 18.7 \\
(19.0)\end{array}$ \\
\hline 6MWD (m) & & $\begin{array}{c}\mathrm{N}=55 \mathrm{I} ; 335.3 \\
(131.1)\end{array}$ \\
\hline \multicolumn{3}{|l|}{ Phenotypes } \\
\hline “Czech" & $\begin{array}{l}\text { Bronchitic } \\
\text { Emphysematous } \\
\text { Bronchiectases/COPD } \\
\text { overlap } \\
\text { Asthma/COPD overlap } \\
\text { Exacerbator } \\
\text { Cachexia }\end{array}$ & $\begin{array}{c}422(58.6 \%) \\
279(79.3 \%) \\
107(31.1 \%) \\
22(3.9 \%) \\
229(31.8 \%) \\
108(15.0 \%)\end{array}$ \\
\hline "Spanish" & $\begin{array}{l}\text { Asthma/COPD overlap } \\
\text { Non-exacerbator } \\
\text { Exacerbator with } \\
\text { emphysema } \\
\text { Exacerbator with chronic } \\
\text { bronchitis }\end{array}$ & $\begin{array}{c}82(11.4 \%) \\
44 \mid(61.3 \%) \\
140(19.4 \%) \\
57(7.9 \%)\end{array}$ \\
\hline GOLD & & \\
\hline Stages $(I-4)$ & $\begin{array}{l}1 \\
2 \\
3 \\
4\end{array}$ & $\begin{array}{c}0(0.0 \%) \\
266(36.9 \%) \\
361(50.1 \%) \\
93(12.9 \%)\end{array}$ \\
\hline Groups 2016 (A-D) & $\begin{array}{l}\text { A } \\
B \\
C \\
D\end{array}$ & $\begin{array}{c}35(4.9 \%) \\
150(20.8 \%) \\
36(5.0 \%) \\
499(69.3 \%)\end{array}$ \\
\hline Groups 2019 (A-D) & $\begin{array}{l}\text { A } \\
\text { B } \\
\text { C } \\
\text { D }\end{array}$ & $\begin{array}{c}61(8.5 \%) \\
380(52.8 \%) \\
10(1.4 \%) \\
269(37.4 \%)\end{array}$ \\
\hline
\end{tabular}


Table I (Continued).

\begin{tabular}{|l|c|c|}
\hline \multicolumn{2}{|l|}{ Prognostic indices } & \\
\hline BODE score & & $\begin{array}{c}\mathrm{N}=55 \mathrm{I} ; 4.2 \\
(2.1)\end{array}$ \\
\hline ADO score & & $4.7(1.6)$ \\
\hline
\end{tabular}

Notes: Categorical parameters are described by absolute (relative) frequencies. Relative frequencies are calculated from valid data. Continuous variables are described by valid $\mathrm{N}$ and mean (standard deviation).

Abbreviations: mMRC, modified Medical Research Council dyspnea scale; CAT, COPD Assessment Test; $\mathrm{FEV}_{1}$, forced expiratory volume in I second; IVC, inspiratory vital capacity; FVC, forced vital capacity; RV, residual volume; TLC, total lung capacity; RV/TLC, residual volume to total lung capacity ratio; IC/TLC, inspiratory capacity to total lung capacity ratio; $\mathrm{TL}_{\mathrm{co}}$, total lung diffusion capacity for carbon monoxide; FeNO, fractional exhaled nitric oxide; ppb, part per billion; m, meter; GOLD, Global Initiative for Chronic Obstructive Lung Disease; BODE, (index) Body-mass index, airflow Obstruction Dyspnoea Exercise capacity; ADO, (index) Age, Dyspnoea, airflow Obstruction.

Questionnaire), pharmacological and non-pharmacological treatment, pulmonary functions and other clinical examinations (computed tomography [CT] of chest, electrocardiogram, blood gases, etc.). ${ }^{13}$

\section{Statistical Analyses}

Of the 784 COPD subjects followed in the CMRD cohort, 64 were excluded due to missing data mandatory for the planned analysis (i.e., data on "Czech" phenotypes, "Spanish" phenotypes, GOLD grades and groups).

Continuous variables were described by N, mean $( \pm \mathrm{SD})$ and median (5th-95th percentile). Absolute and relative frequencies were used to describe categorical parameters. Relative frequencies were calculated from the complete data.

Kaplan-Meier (KM) survival analysis was used for mortality assessment. We calculated survival rates at pre-defined time points (12, 24, 36, 48, and 60 months), supplemented by $95 \%$ confidence intervals $(95 \% \mathrm{CI})$, for all six elementary "Czech" phenotypes, "Spanish" phenotypes, GOLD stages and GOLD groups. If median survival was reached, also these data were supplemented, including 95\% CI. Statistically significant differences were tested by Log Rank test. KM graphs for the six elementary phenotypes were constructed upon simple basis of presence vs. absence of the phenotype and if this relates to increased risk of death. According to the Czech phenotyping scheme of COPD, one patient may have more than one phenotype concurrently. Therefore, we constructed additional KM graphs also for the most frequent combinations of phenotypes in our cohort and analyzed their association with risk of mortality.

An analysis of factors underlying mortality risk in our cohort was performed with the use of classification and regression tree (CART) analysis. In step 1, various disease characteristics and factors were compared between deceased and living patients (emphysema, cachexia, frequent exacerbations, history of sleep apnoea, $\mathrm{FEV}_{1} \%$ pred., systemic arterial hypertension, arterial blood gases $\left[\mathrm{PaO}_{2}, \mathrm{PaCO}_{2}\right]$, history of chronic heart failure [CHF], distance covered during six-minute walk test [6-MWT]). Only factors showing significant difference were entered into the CART model (step 2).

\section{Results}

Data of 720 subjects of the CMRD cohort were complete and eligible for mortality analyses in relation to "Czech" phenotypes, "Spanish" phenotypes and GOLD grades and groups. ${ }^{2,6,14-17}$

Baseline characteristics of the cohort $(\mathrm{n}=720)$ are presented in Table 1. Briefly, the cohort was composed of $73.1 \%$ men, $90.3 \%$ were current or past smokers, mean age at inclusion was 66.6 years, mean body mass index (BMI) was $27.1 \mathrm{~kg} / \mathrm{m}^{2}$ and mean $\mathrm{FEV}_{1}$ was $44.4 \%$ pred. Distribution of subjects across GOLD grades and groups showed GOLD grade 3 (according to the GOLD pre-2011 classification scheme) and GOLD group B (using the 2017-present classification scheme) being most abundant patient categories (50.1\% and $52.8 \%$, respectively). Patient assignment to "Spanish" phenotypes and "Czech" phenotypes showed non-exacerbators (for Spanish phenotyping system) and emphysematous (for "Czech" phenotypes) patients being most frequent in the cohort with $61.3 \%$ and $79.3 \%$, respectively (Table 1 ).

The survival analyses showed the following results: for the "Czech" phenotypes, bronchiectases/COPD overlap (HR 1.425, $\mathrm{p}=0.045$ ), frequent exacerbator (HR 1.58, $\mathrm{p}<0.001$ ), cachexia (HR 2.262, $\mathrm{p}<0.001$ ) and emphysematous (HR 1.786, $\mathrm{p}=0.015$ ) were associated with higher long-term risk of death. On the contrary, the presence of ACO was clearly associated with better outcome (HR 0.17, $\mathrm{p}=0.005$ ). Patients with chronic bronchitis had slightly higher mortality risk, but the difference was not significant $(\mathrm{p}=0.356)$ (Figure $1 \mathrm{~A}-\mathrm{F})$. The mortality risk with the six elementary clinical phenotypes couldn't be directly compared since, by definition, one patient may be present with more phenotypes concurrently and this didn't allow for a face-to-face comparison. However, we put all the six phenotypes in a single KM graph but this was only for illustrative purpose (Supplementary Graph 1).

For "Spanish" phenotypes, $\mathrm{AE} \mathrm{CB}$ and $\mathrm{AE}$ non-CB phenotypes were associated with significantly greater risk of long-term mortality (HR 1.787 and 2.001, respectively; 
$\mathrm{p}=0.001$ ) compared to ACO and NE phenotypes (Figure 2).

Co-presence of multiple ("Czech") phenotypes in a single patient had significant additive effect on mortality risk (Figure $3 \mathrm{~A}$ and $\mathrm{B}$ ). Patients with a combination of emphysema, cachexia and a history of frequent exacerbations had the poorest prognosis with HR 3.075 $(\mathrm{p}<0.001)$ and a five-year probability of death as high as $77.6 \%$ compared to COPD subjects possessing these three concurrent clinical phenotypes. Survival estimates

A

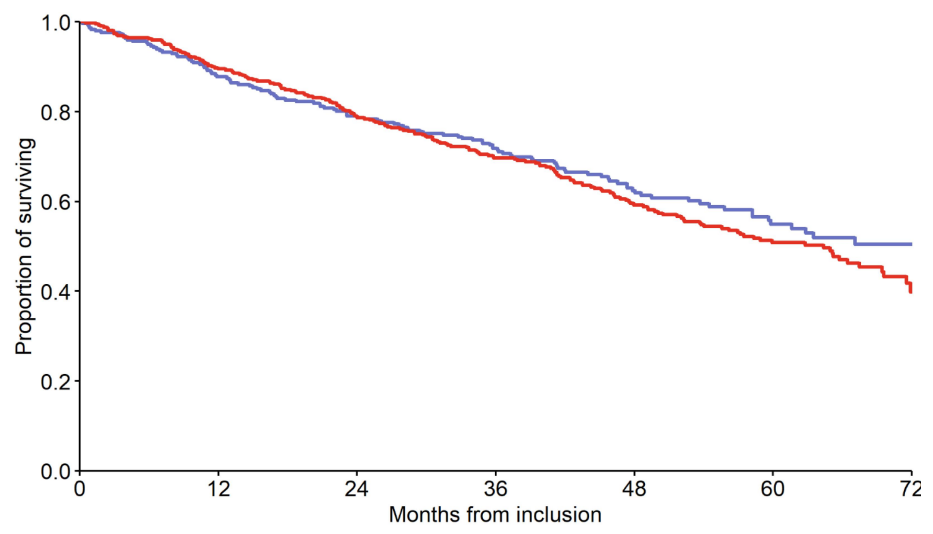

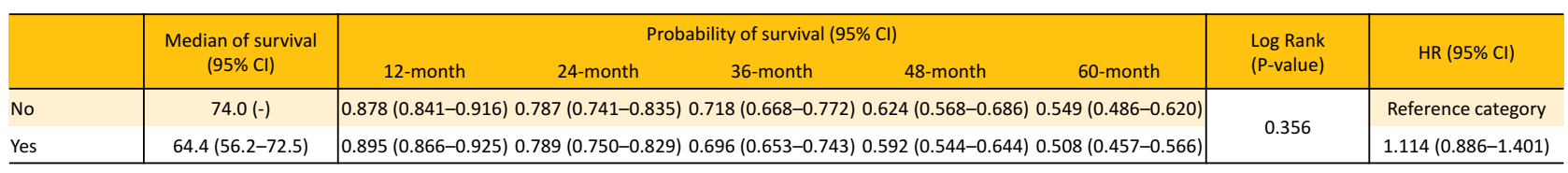

\begin{tabular}{|c|c|}
\hline 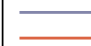 & $\begin{array}{l}\text { No }(\mathrm{N}=298) \\
\text { Yes }(\mathrm{N}=422)\end{array}$ \\
\hline
\end{tabular}

B

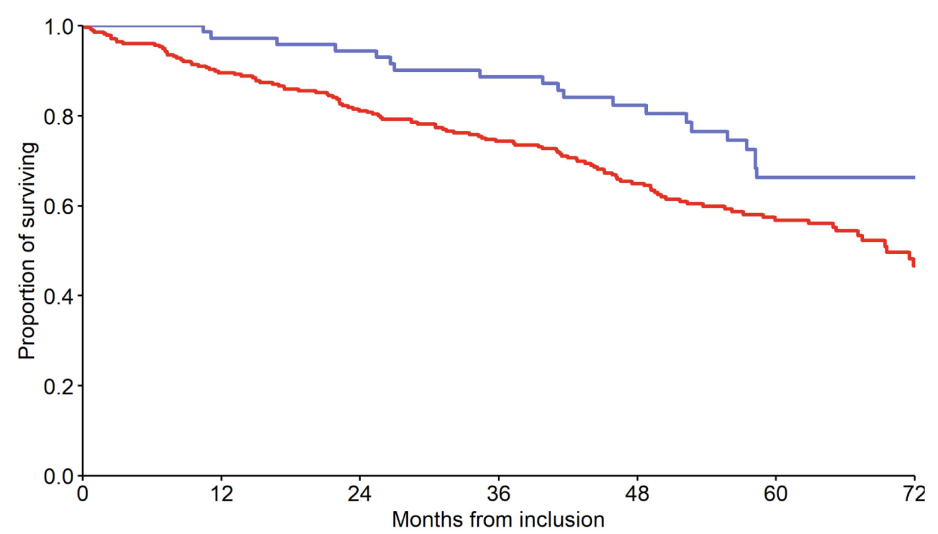

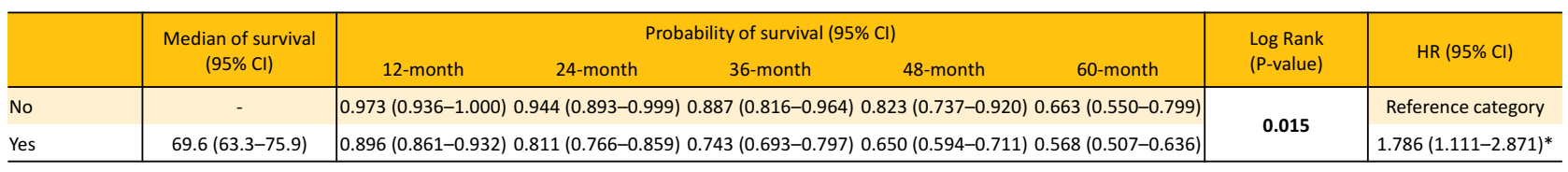

\begin{tabular}{|c|c|}
\hline 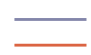 & $\begin{array}{l}\text { No }(N=73) \\
\text { Yes }(N=279)\end{array}$ \\
\hline
\end{tabular}

Figure I Continued. 
C

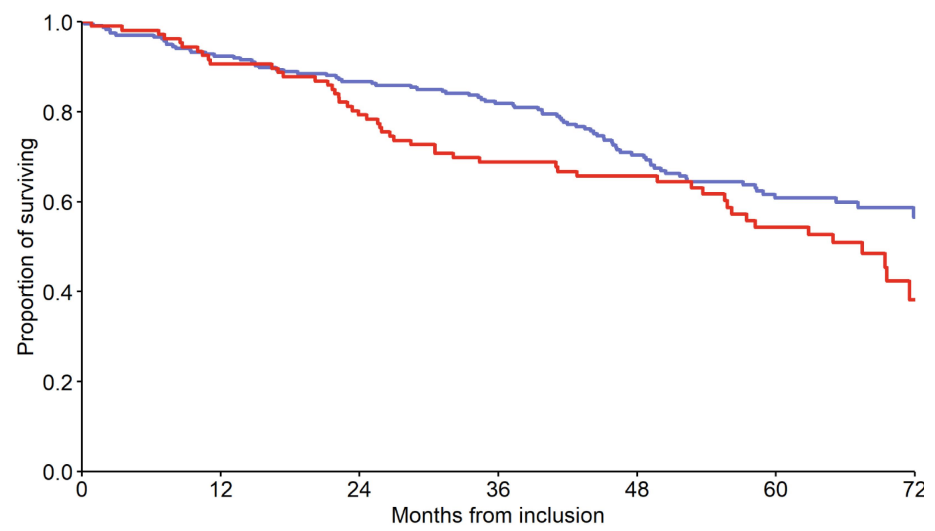

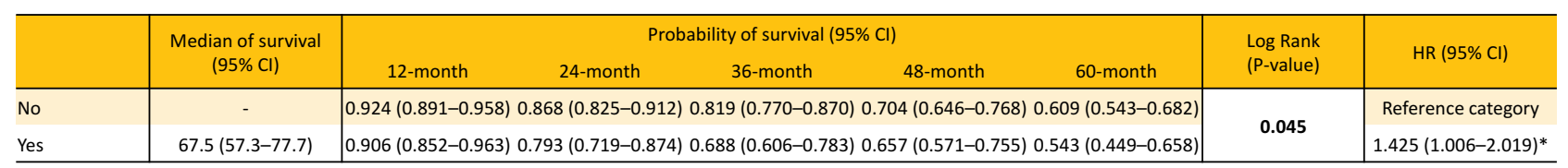

\begin{tabular}{|c|c|}
\hline 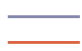 & $\begin{array}{l}\text { No }(N=237) \\
\text { Yes }(N=107)\end{array}$ \\
\hline
\end{tabular}

D

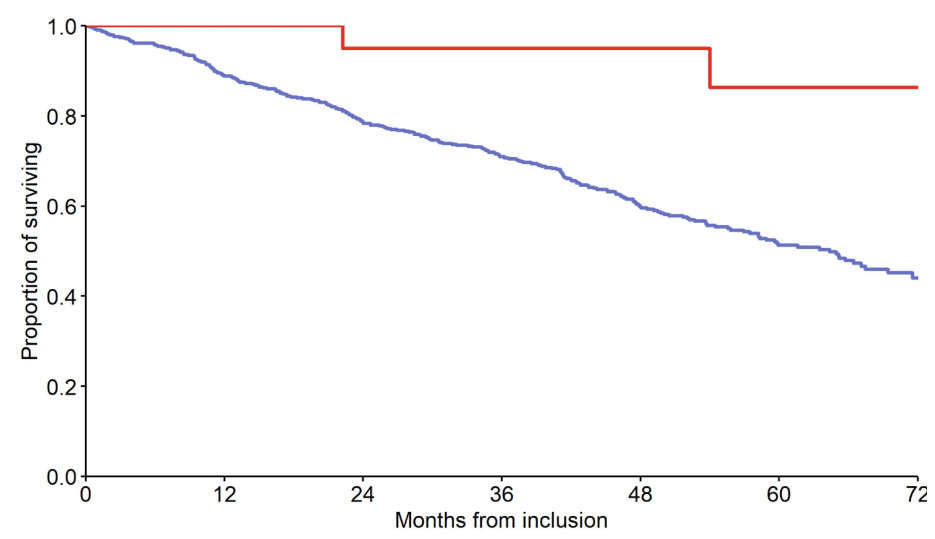

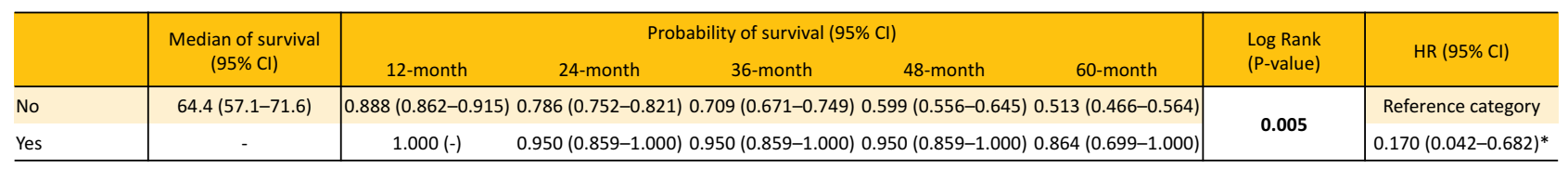

\begin{tabular}{|c|c|}
\hline 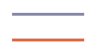 & $\begin{array}{l}\text { No }(N=549) \\
\text { Yes }(N=22)\end{array}$ \\
\hline
\end{tabular}

Figure I Continued. 


\section{E}

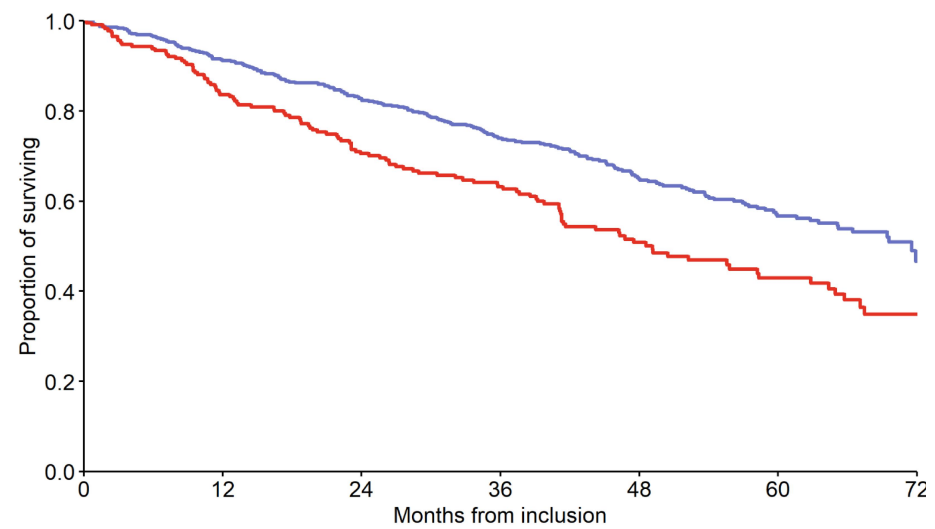

\begin{tabular}{|c|c|c|c|c|c|c|c|c|}
\hline & \multirow{2}{*}{$\begin{array}{l}\text { Median of survival } \\
(95 \% \mathrm{Cl})\end{array}$} & \multicolumn{5}{|c|}{ Probability of survival $(95 \% \mathrm{CI})$} & \multirow{2}{*}{$\begin{array}{l}\text { Log Rank } \\
\text { (P-value) }\end{array}$} & \multirow{2}{*}{ HR (95\% Cl) } \\
\hline & & 12-month & 24-month & 36-month & 48-month & 60-month & & \\
\hline No & $71.5(65.2-77.9)$ & $0.912(0.887-0$. & $26(0.793-0.8$ & $39(0.701-0.7$ & $49(0.606-0.6$ & $67(0.519-0.620)$ & & Reference category \\
\hline Yes & $49.1(39.2-59.0)$ & $0.836(0.789-0$. & $05(0.647-0.7$ & $32(0.570-0.7$ & $08(0.442-0.5$ & $29(0.359-0.513)$ & & $1.580(1.255-1.989)^{*}$ \\
\hline
\end{tabular}

\begin{tabular}{ll|}
$\longrightarrow$ & No $(N=491)$ \\
Yes $(N=229)$
\end{tabular}

$\mathbf{F}$

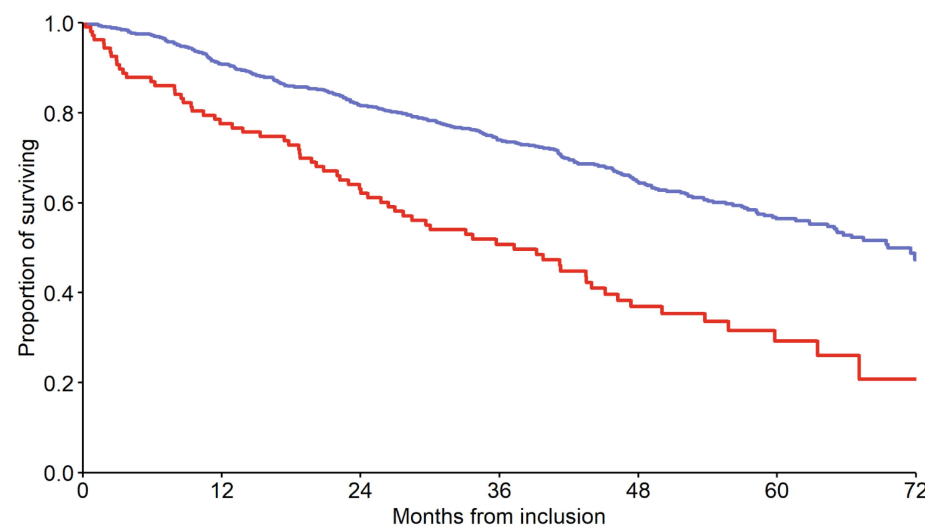

\begin{tabular}{|c|c|c|c|c|c|c|c|c|}
\hline & \multirow{2}{*}{$\begin{array}{l}\text { Median of survival } \\
(95 \% \mathrm{Cl})\end{array}$} & \multicolumn{5}{|c|}{ Probability of survival $(95 \% \mathrm{CI})$} & \multirow{2}{*}{$\begin{array}{l}\text { Log Rank } \\
\text { (P-value) }\end{array}$} & \multirow{2}{*}{ HR $(95 \%$ CI) } \\
\hline & & 12-month & 24-month & 36-month & 48-month & 60-month & & \\
\hline No & $69.6(64.0-75.2)$ & $0.908(0.885-0$. & $0.816(0.785-0.8$ & $.740(0.705-0$. & $646(0.607-0.6$ & $0.564(0.521-0.612)$ & \multirow{2}{*}{$<0.001$} & Reference category \\
\hline Yes & $37.3(26.2-48.4)$ & $0.776(0.701-0$. & $0.631(0.545-0.7$ & $.508(0.419-0$. & $369(0.282-0$. & $.293(0.205-0.418)$ & & $2.262(1.726-2.965)^{*}$ \\
\hline
\end{tabular}

$\begin{array}{ll}\longrightarrow & \text { No }(\mathrm{N}=612) \\ & \text { Yes }(\mathrm{N}=108)\end{array}$

Figure I (A-F) Long-term survival according to presence / absence of "Czech" phenotypes: bronchitic (A), emphysematous (B), bronchiectases / COPD overlap (C), asthma / COPD overlap (D), frequent exacerbator (E) and pulmonary cachexia (F).

Notes: Yes $=$ the phenotype is present, No $=$ the phenotype is absent. Statistically significant differences are in bold. *Statistically significant difference versus reference category.

for the GOLD grades and groups showed GOLD stage IV (HR 2.42) and group D (HR 2.77) be associated with worst outcome (both $\mathrm{p}<0.001$ ) (Supplementary Figures $\underline{2 a-c)}$. Age- and sex-adjusted results of uni- and multivariate Cox models are presented in Supplementary Tables 1 and 2 .

The CART analysis showed three factors $\left(\mathrm{FEV}_{1} \%\right.$ pred., pulmonary cachexia and chronic heart failure in 


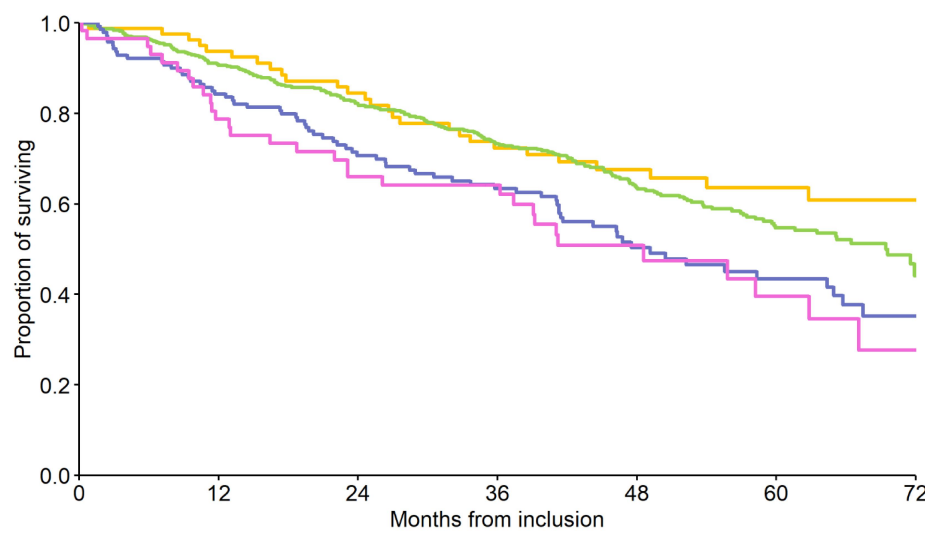

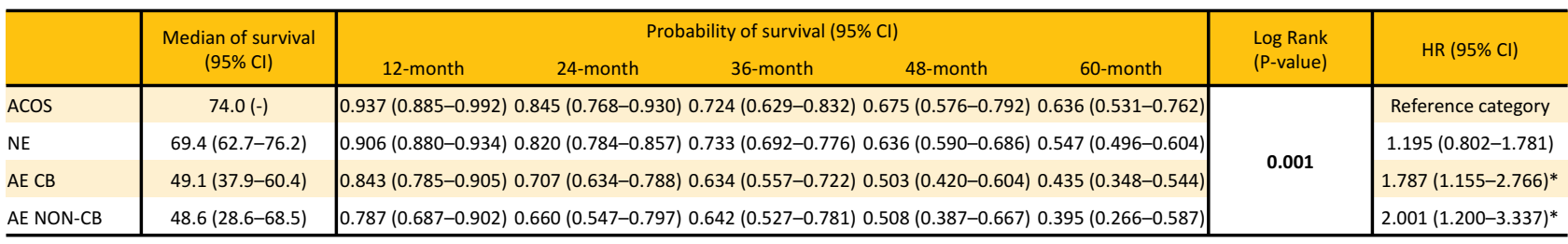

Figure 2 Long-term survival according to "Spanish" phenotypes.

Notes: Statistically significant differences are in bold. *Statistically significant difference versus reference category.

Abbreviations: ACO,Asthma / COPD overlap; AE CB, exacerbator with chronic bronchitis; $A E$ non-CB, exacerbator with emphysema; NE, non-exacerbator.

patient history $[\mathrm{CHF}]$ ) having discriminative power to categorize patients into risk groups with $\mathrm{FEV}_{1} \%$ pred. being the key parameter determining long-term outcome. The two clusters with highest mortality risk were $\mathrm{FEV}_{1}$ pred. $\leq 40 \%$ plus cachexia (HR 3.958), and $\mathrm{FEV}_{1}$ pred. $\leq 40 \%$ plus presence of CHF (HR 3.99), both $\mathrm{p}<0.001$ (Supplementary Figures 3a and 3b).

\section{Discussion}

Apart from guidance towards specific treatments, phenotypes may also have prognostic importance. In a recent study from Spain, the authors demonstrated that the Spanish ACO and NE phenotypes were associated with a more favourable outcome when compared to the two exacerbator phenotypes. ${ }^{12,18}$ This is in full accordance with our results that showed similar patterns of mortality risk when using "Spanish" phenotypes as COPD classification. ${ }^{12,18,19}$ Besides, our data showed similar mortality patterns also for the GOLD groups and stages. ${ }^{20}$ This confirms similar composition of our cohort to previous study cohorts and good reproducibility of our data. ${ }^{12,19,20}$

In our study, the presence of four "Czech" COPD phenotypes was associated with increased risk of death, namely the frequent exacerbators, bronchiectases/COPD overlap, cachectic and emphysematous patients. ${ }^{6,21}$ Emphysema is a frequent clinical feature of COPD and a well known driver of morbidity and mortality. ${ }^{22}$ The underlying mechanism of mortality in emphysematous patients is loss of functional parenchyma leading to ventilatory/perfusion (V/Q) mismatch and respiratory failure. ${ }^{23}$ Cachexia (BMI $<21 \mathrm{~kg} / \mathrm{m}^{2}$ ) is an independent factor associated with risk of death, constituting also the BODE index, a worldwide-used prognostic instrument for mortality risk prediction. ${ }^{24-27}$ Frequent exacerbations lead to accelerated deterioration of lung functions and decreased exercise capacity, resulting in disability, loss of quality of life and increased morbidity and mortality. ${ }^{28,29}$

The main message of our work is that certain "Czech" phenotypes are linked with higher mortality risk, and that the risk is amplified if coupling of multiple phenotypes occurs. The combination of emphysema, cachexia and frequent exacerbations was associated with highest risk (HR 3.075). In some aspects, similar results were obtained in the COPDGene study where a combination of emphysema-predominant and airway-predominant disease subtype linked to highest risk of all-cause mortality. ${ }^{22}$ Compared to lower-risk subtypes of COPD, emphysema- and airway-predominant patients had significantly higher BODE score and higher exacerbation rate. $^{22}$

The CART analysis identified $\mathrm{FEV}_{1}$, CHF in patient history and cachexia as the three main factors underlying mortality risk in our cohort. $\mathrm{FEV}_{1}$ pred. $\leq 40 \%$ was the key 
A

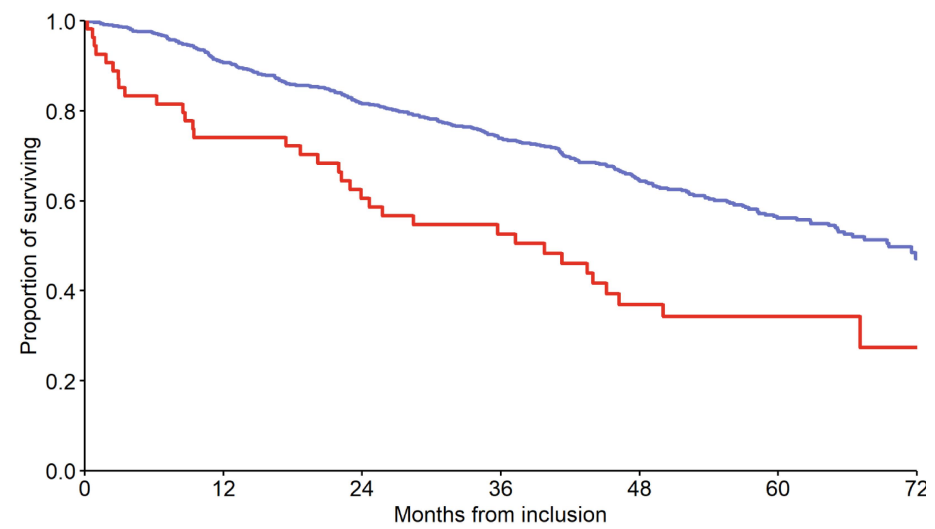

\begin{tabular}{|c|c|c|c|c|c|c|c|c|}
\hline \multirow{2}{*}{\multicolumn{2}{|c|}{$\begin{array}{c}\text { Median of survival } \\
(95 \% \mathrm{CI})\end{array}$}} & \multicolumn{5}{|c|}{ Probability of survival $(95 \% \mathrm{Cl})$} & \multirow{2}{*}{$\begin{array}{l}\text { Log Rank } \\
\text { (P-value) }\end{array}$} & \multirow{2}{*}{ HR (95\% Cl) } \\
\hline & & 12-month & 24-month & 36-month & 48-month & 60-month & & \\
\hline No & $69.6(64.2-75.0)$ & $0.907(0.884-0$ & $16(0.785-0.8$ & $739(0.704-0.7)$ & $646(0.607-0$. & $562(0.518-0.609)$ & & Reference category \\
\hline Yes & $39.8(20.7-58.8)$ & $0.741(0.633-0$. & $06(0.487-0.7$ & $526(0.406-0.6$ & $369(0.255-0.5$ & $343(0.231-0.510)$ & & $2.156(1.505-3.088)^{*}$ \\
\hline
\end{tabular}

\begin{tabular}{ll|}
$\square$ & No $(\mathrm{N}=617)$ \\
& Yes $(\mathrm{N}=54)$ \\
\hline
\end{tabular}

B

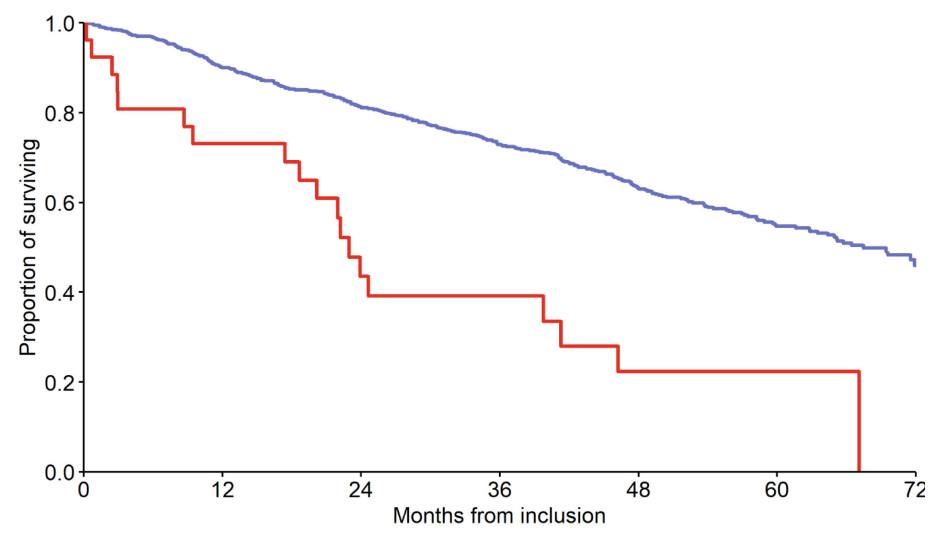

\begin{tabular}{|c|c|c|c|c|c|}
\hline & \multirow{2}{*}{$\begin{array}{l}\text { Median of survival } \\
\qquad(95 \% \mathrm{Cl})\end{array}$} & \multicolumn{2}{|c|}{ Probability of survival ( $95 \% \mathrm{CI})$} & \multirow{2}{*}{$\begin{array}{l}\text { Log Rank } \\
\text { (P-value) }\end{array}$} & \multirow{2}{*}{$\mathrm{HR}(95 \% \mathrm{Cl})$} \\
\hline & & 24-month & 60 -month & & \\
\hline No & $67.5(61.1-73.8)$ & $0.900(0.877-0.923) 0.812(0.783-0.842)$ & $0.729(0.696-0.764) 0.632(0.594-0.672) 0.547(0.505-0.592)$ & $<0.001$ & Reference category \\
\hline
\end{tabular}

\begin{tabular}{|c|c|}
\hline 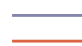 & $\begin{array}{l}\text { No }(\mathrm{N}=675) \\
\text { Yes }(\mathrm{N}=26)\end{array}$ \\
\hline
\end{tabular}

Figures 3 (A and B) Long-term survival according to presence of combination of "Czech" phenotypes: emphysematous and cachexia (A) and emphysematous and cachexia and frequent exacerbator $(\mathbf{B})$.

Notes: Yes $=$ the combination of phenotypes is present, No $=$ the combination of phenotypes is absent. Statistically significant differences are in bold. $*$ Statistically significant difference versus reference category.

determinant of poor outcome. If $\mathrm{FEV}_{1}$ pred. $\leq 40 \%$ coincided with cachexia or CHF, 5-year mortality risk was as high as $>79 \%$ and $>76 \%$, respectively. Both poor lung functions (i.e., $\mathrm{FEV}_{1} \leq 40 \%$ ) and presence of CHF represent serious health problems and also may link together. ${ }^{30} \mathrm{FEV}_{1}$ is the main parameter consistently used for objective assessment of COPD severity in clinical trials but also in daily clinical practice. ${ }^{30} \mathrm{CHF}$ is a severe affection of a vital organ and is considered rather a comorbidity, though pathophysiologically strongly linked to COPD per se. Previous research identified 
CHF as one of the strongest predictors of death in COPD patients. $^{31-34}$ Prognostic importance of cachexia has been discussed above.

There are limitations of our study. First, the CMRD cohort included patients mainly from tertiary and university-type centers. In consequence, our cohort didn't include GOLD grade I patients. On the other hand, grade I patients tend to be un-/mis-diagnosed in real-life settings, while grade II-IV patients constitute the majority of physicians' practice. Above that, the cohort is mainly composed of COPD patients with pulmonary emphysema, possibly due to non-inclusion of mild cases. This may introduce another bias to the results and their interpretation. Second, the majority of cohort was composed of men (73.1\%) introducing a possible gender bias. This resembles, however, normal composition of patients in the Czech Republic where men constitute around $60-70 \%$ of COPD population. Third, the "Czech" phenotypes concept has some limitations. Computed tomography may be of limited accessibility in certain regions. However, CT scans are crucial to diagnose emphysema and/or bronchiectases. The latter means that COPD individuals with absent chest CT may be undiagnosed with emphysema or bronchiectases and these phenotypes may be missed by the clinician. Another issue is the lack of scientific data regarding individualized treatment. The Czech Multicenter Research Database of COPD cohort is rather a smaller (or medium-sized) cohort that was however large enough to show significant differences in mortality in relation to clinical phenotypes of COPD and their combinations. Finally, the discussed GOLD grades (I-IV), GOLD groups (A-D), "Spanish" and "Czech" phenotypes are not intended primarily for prognosis assessment. However, for clinicians in the daily practice, rapid identification of high-risk patients may be very helpful in terms of better case management.

\section{Conclusion}

Certain "Czech" phenotypes of COPD (bronchiectases/ COPD overlap, frequent exacerbator, pulmonary cachexia and emphysematous) are associated with higher risk of death. If certain phenotypes are co-present (emphysematous AND cachectic AND frequent exacerbator) in a single individual, this translates into amplified risk of death.

\section{Abbreviations}

ACO, Asthma and COPD Overlap; AE CB, Exacerbator with Chronic Bronchitis (Spanish phenotype); AE non-CB, Exacerbator with Emphysema (Spanish phenotype); BMI,
Body Mass Index; BODE, (index) Body-Mass Index, Airflow Obstruction, Dyspnoea, Exercise Capacity; CART, Classification and Regression Tree; CAT, COPD Assessment Test; CHF, Chronic Heart Failure; CMRD, Czech Multicenter Research Database of COPD; COPD, Chronic Obstructive Pulmonary Disease; CT, Chest Tomography; $\mathrm{FEV}_{1}$, Forced Expiratory Volume in 1second; GOLD, Global Initiative for Chronic Obstructive Lung Disease; HR, Hazard Ratio; KM, Kaplan-Meier (survival estimate); mMRC, modified Medical Research Council scale; NE, non-exacerbator (Spanish phenotype); RCT, Randomized Controlled Trial; SD, Standard Deviation; V/ Q, Ventilatory / Perfusion mismatch.

\section{Ethics}

The CMRD project is being conducted in accordance with the Declaration of Helsinki and the Czech and European Union laws. The CMRD study, its protocol and the use of any collected anonymized data for scientific purposes were approved by the Multicenter Ethics Committee of Masaryk University, Brno, Czech Republic (date of approval: 2013, Jan 16th, protocol code: CHOPN) as well as by regional review boards of all 14 participating centers. ${ }^{13}$ No further ethics approvals are requested by the steering committee for particular analyses. All patients signed a written informed consent at enrollment and agreed to use their anonymized data for scientific purpose. Signed written consent was one of the basic inclusion criteria. The data from the CMRD Registry is available upon reasonable scientific request on the steering committee of the project.

\section{Acknowledgments}

The authors would like to thank to all the physicians participating in the CMRD study, as well as to nursing staff and to all patients willing to share their data with the scientific community. Presented as oral presentation at the Virtual Conference of the European Respiratory Society ( $7^{\text {th }}$ September 2020).

\section{Author Contributions}

All authors contributed to data analysis, drafting or revising the article, have agreed on the journal to which the article will be submitted, gave final approval of the version to be published, and agree to be accountable for all aspects of the work. 


\section{Funding}

The CMRD research project has been funded by Ministry of Health of the Czech Republic (15/14/NAP, 5/15/NAP, UHHK 00179906, MH CZ-DRO FNBr 65269705), the Charles University in Prague (PROGRES Q40, and PROGRES Q42), and a consortium of several pharmaceutical companies (Angelini, AstraZeneca, Boehringer Ingelheim, Cipla, CSL Behring, GSK, Novartis, and Sandoz). All companies supported the CMRD project via unrestricted research grants. The sponsors had no role in the design of the study, data collection and analysis or in preparation of the manuscript. The opinions, results, and conclusions reported in this article are completely independent on the funding sources.

\section{Disclosure}

Dr Kristian Brat reports personal fees from Boehringer Ingelheim, AstraZeneca, Chiesi, payments for advisory boards from Boehringer Ingelheim and Chiesi; educational support from Boehringer Ingelheim, Angelini, and CSL Behring, outside the submitted work. Dr Jaromir Zatloukal reports personal fees from Boehringer-Ingelheim, GlaxoSmithKline, AstraZeneca, Chiesi, and Angelini, outside the submitted work. Dr Marek Plutinsky reports lecture fees from Boehringer Ingelheim, Berlin Chemie, and CSL Behring; educational support from Boehringer Ingelheim and CSL Behring, outside the submitted work. Prof. Dr. Vladimir Koblizek reports COPD research funding from Boehringer Ingelheim and Novartis, and received consulting/lectures payments from Angelini, AstraZeneca, Berlin-Chemie, Boehringer Ingelheim, GSK, Novartis and Chiesi pertaining to the COPD field within the past 3 years. The authors report no other conflicts of interest in this work.

\section{References}

1. GBD. 2017 causes of death collaborators. Global, regional, and national age-sex-specific mortality for 282 causes of death in 195 countries and territories, 1980-2017: a systematic analysis for the Global Burden of Disease Study 2017. Lancet. 2018;392(10159):1736-1788.

2. Miravitlles M, Soler-Cataluña JJ, Calle M, et al. Spanish guidelines for management of chronic obstructive pulmonary disease (GesEPOC) 2017. Pharmacological treatment of stable phase. Arch Bronconeumol. 2017;53 (6):324-335. doi:10.1016/j.arbres.2017.03.018

3. Agusti A, Bel E, Thomas M, et al. Treatable traits: toward precision medicine of chronic airway diseases. Eur Respir J. 2016;47(2):410 419. doi:10.1183/13993003.01359-2015

4. McDonald VM, Fingleton J, Agusti A, et al.; Participants of the Treatable Traits Down Under International Workshop; Treatable Traits Down Under International Workshop participants. Treatable traits: a new paradigm for 21 st century management of chronic airway diseases: treatable traits down under international workshop report. Eur Respir J. 2019;53 (5):1802058. doi:10.1183/13993003.02058-2018
5. Ulrik CS, Vijverberg S, Hanania NA, Diamant Z. Precision medicine and treatable traits in chronic airway diseases - where do we stand? Curr Opin Pulm Med. 2020;26(1):33-39. doi:10.1097/MCP.00000 00000000639

6. Zatloukal J, Brat K, Neumannova K, et al. Chronic obstructive pulmonary disease - diagnosis and management of stable disease; a personalized approach to care, using the treatable traits concept based on clinical phenotypes. Position paper of the Czech pneumological and phthisiological society. Biomed Pap Med Fac Univ Palacky Olomouc Czech Repub. 2020;164(4):325-356. doi:10.5507/bp.2020.056

7. Miravitlles M, Vogelmeier C, Roche N, et al. A review of national guidelines for management of COPD in Europe. Eur Respir J. 2016;47(2):625-637. doi:10.1183/13993003.01170-2015

8. Miravitlles M, Soler-Cataluña JJ, Calle M, et al.; Spanish Society of Pulmonology and Thoracic Surgery. Spanish COPD Guidelines (GesEPOC): pharmacological treatment of stable COPD. spanish society of pulmonology and thoracic surgery. Arch Bronconeumol. 2012;48(7):247-257. doi:10.1016/j.arbres.2012.04.001

9. Zatloukal J, Volakova E, Koblizek V, et al. Phenotype-based therapy of COPD: effect on the rate of COPD exacerbations. Eur Respir J. 2018;52(suppl 62):PA3860.

10. Vukoja M, Kopitovic I, Lazic Z, et al. Diagnosis and management of chronic obstructive pulmonary disease in Serbia: an expert group position statement. Int $J$ Chron Obstruct Pulmon Dis. 2019;14:1993-2002. doi:10.2147/COPD.S214690

11. Zykov KA, Ovcharenko SI. Approaches to drug therapy for COPD in Russia: a proposed therapeutic algorithm. Int J Chron Obstruct Pulmon Dis. 2017;12:1125-1133. doi:10.2147/COPD.S125594

12. Golpe R, Suárez-Valor M, Martín-Robles I, et al. Mortality in COPD patients according to clinical phenotypes. Int J Chron Obstruct Pulmon Dis. 2018;13:1433-1439. doi:10.2147/COPD.S159834

13. Novotna B, Koblizek V, Zatloukal J, et al. Czech multicenter research database of severe COPD. Int J Chron Obstruct Pulmon Dis. 2014;9:1265-1274. doi:10.2147/COPD.S71828

14. Rabe KF, Hurd S, Anzueto A, et al. Global Initiative for chronic obstructive lung disease. Global strategy for the diagnosis, management, and prevention of chronic obstructive pulmonary disease: GOLD executive summary. Am J Respir Crit Care Med. 2007;176 (6):532-555. doi:10.1164/rccm.200703-456SO

15. Vogelmeier CF, Criner GJ, Martinez FJ, et al. Global strategy for the diagnosis, management, and prevention of chronic obstructive lung disease 2017 Report. GOLD executive summary. Am J Respir Crit Care Med. 2017;195(5):557-582. doi:10.1164/rccm.201701-0218PP

16. Singh D, Agusti A, Anzueto A, et al. Global strategy for the diagnosis, management, and prevention of chronic obstructive lung disease: the GOLD science committee report 2019. Eur Respir J. 2019;53(5):1900164. doi:10.1183/13993003.00164-2019

17. Vestbo J, Hurd SS, Agustí AG, et al. Global strategy for the diagnosis, management, and prevention of chronic obstructive pulmonary disease: GOLD executive summary. Am J Respir Crit Care Med. 2013;187(4):347-365. doi:10.1164/rccm.201204-0596PP

18. Hernández Vázquez J, Ali García I, Jiménez-García R, et al. COPD phenotypes: differences in survival. Int J Chron Obstruct Pulmon Dis. 2018;13:2245-2251. doi:10.2147/COPD.S166163

19. Calle Rubio M, Casamor R, Miravitlles M. Identification and distribution of COPD phenotypes in clinical practice according to Spanish COPD guidelines: the FENEPOC study. Int J Chron Obstruct Pulmon Dis. 2017;12:2373-2383. doi:10.2147/COPD. $\mathrm{S} 137872$

20. Cabrera López C, Casanova Macario C, Marín Trigo JM, et al. Comparison of the 2017 and 2015 global initiative for chronic obstructive lung disease reports. Impact on grouping and outcomes. Am J Respir Crit Care Med. 2018;197(4):463-469. doi:10.1164/rccm.201707-1363OC

21. Brat K, Plutinsky M, Koblizek V, et al. Cluster phenotyping as an approach to identify COPD patients at risk of poor prognosis. Eur Respir J. 2018;52(suppl 62):PA3853. 
22. Young KA, Regan EA, Han MK, et al. COPDGene ${ }^{\circledR}$ Investigators. Subtypes of COPD have unique distributions and differential risk of mortality. Chronic Obstr Pulm Dis. 2019;6(5):400-413. doi:10. 15326/jcopdf.6.5.2019.0150

23. Sarkar M, Niranjan N, Banyal PK. Mechanisms of hypoxemia. Lung India. 2017;34(1):47-60. doi:10.4103/0970-2113.197116

24. Schols AM, Slangen J, Volovics L, Wouters EF. Weight loss is a reversible factor in the prognosis of chronic obstructive pulmonary disease. Am J Respir Crit Care Med. 1998;157(6 Pt 1):1791-1797. doi:10.1164/ajrccm.157.6.9705017

25. Landbo C, Prescott E, Lange P, Vestbo J, Almdal TP. Prognostic value of nutritional status in chronic obstructive pulmonary disease. Am J Respir Crit Care Med. 1999;160(6):1856-1861. doi:10.1164/ ajrccm.160.6.9902115

26. McDonald MN, Wouters EFM, Rutten E, et al. It's more than low BMI: prevalence of cachexia and associated mortality in COPD. Respir Res. 2019;20(1):100. doi:10.1186/s12931-019-1073-3

27. Celli BR, Cote CG, Marin JM, et al. The body-mass index, airflow obstruction, dyspnea, and exercise capacity index in chronic obstructive pulmonary disease. N Engl J Med. 2004;350(10):1005-1012. doi:10.1056/NEJMoa021322

28. Suissa S, Dell'Aniello S, Ernst P. Long-term natural history of chronic obstructive pulmonary disease: severe exacerbations and mortality. Thorax. 2012;67(11):957-963. doi:10.1136/thoraxjnl-20 11-201518
29. Hillas G, Perlikos F, Tzanakis N. Acute exacerbation of COPD: is it the "stroke of the lungs"? Int J Chron Obstruct Pulmon Dis. 2016;11:1579-1586. doi:10.2147/COPD.S106160

30. Franssen FM, Alter P, Bar N, et al. Personalized medicine for patients with COPD: where are we? Int J Chron Obstruct Pulmon Dis. 2019;14:1465-1484. doi:10.2147/COPD.S175706

31. Pikoula M, Quint JK, Nissen F, Hemingway H, Smeeth L, Denaxas S. Identifying clinically important COPD sub-types using data-driven approaches in primary care population based electronic health records. BMC Med Inform Decis Mak. 2019;19(1):86. doi:10.1186/s12911-0190805-0

32. Burgel PR, Paillasseur JL, Janssens W, et al. Initiatives BPCO, EABPCO, Leuven and 3CIA study groups. A simple algorithm for the identification of clinical COPD phenotypes. Eur Respir J. 2017;50(5):1701034. doi:10.1183/13993003.010 34-2017

33. Aramburu A, Arostegui I, Moraza J, et al. COPD classification models and mortality prediction capacity. Int $J$ Chron Obstruct Pulmon Dis. 2019;14:605-613. doi:10.2147/ COPD.S184695

34. Brat K, Svoboda M, Hejduk K, et al. Introducing a new prognostic instrument for long-term mortality prediction in COPD patients: the CADOT index. Biomed Pap Med Fac Univ Palacky Olomouc Czech Repub. 2020. doi:10.5507/bp.2020.035

\section{Publish your work in this journal}

The International Journal of COPD is an international, peer-reviewed journal of therapeutics and pharmacology focusing on concise rapid reporting of clinical studies and reviews in COPD. Special focus is given to the pathophysiological processes underlying the disease, intervention programs, patient focused education, and self management protocols. This journal is indexed on PubMed Central, MedLine and CAS. The manuscript management system is completely online and includes a very quick and fair peer-review system, which is all easy to use. Visit http://www.dovepress.com/testimonials.php to read real quotes from published authors. 